\title{
Paths to engagement combining sound, animation and interactivity: a comparative evaluation of three net art projects
}

\author{
Nuno N. Correia \\ Goldsmiths, University of London \\ Department of Computing, Embodied Audiovisual Interaction Group \\ New Cross, London, SE14 6NW, UK \\ E-mail: nc@goldsmithsdigital.com
}

\begin{abstract}
This paper compares three net art projects combining sound and animation by the author and André Carrilho (under the name Video Jack): AVOL, Master and Margarita and $A V$ Clash. They follow a development path aiming to create projects enabling integrated audiovisual creativity that are flexible, intuitive, playful to use and engaging to experience. The comparative evaluation of the projects focuses on the analysis of the answers to an online questionnaire. The projects are also contextualized with related works. The methodology for the research is presented, with an emphasis on experience-focused human-computer interaction perspectives. The results of the questionnaire are then discussed. Conclusions are reached regarding the development path, showing that $A V$ Clash has been more successful than previous projects in reaching its objectives, but that it still contains several weaknesses. Strengths detected in previous projects AVOL and Master and Margarita are analysed. Finally, paths for future development are presented.
\end{abstract}

Keywords: audiovisual; multi-sensorial; visual music; animation; sound; evaluation; experience focused; human-computer interaction; interactivity; usability; creativity; engagement; new media art; net art.

Biographical notes: Nuno N. Correia is a researcher, media artist and musician. He is interested in enabling interactive multi-sensorial experiences. Since 2000, he has been teaching and conducting research in media art and design, in universities in Portugal, Finland and the UK. Nuno holds a Doctor of Arts degree in new media from Aalto University (Media Lab Helsinki), with the thesis "Interactive Audiovisual Objects", and a M.Sc. in innovation management from the Technical University of Lisbon. Currently, he is a researcher at Goldsmiths, University of London (EAVI group), working on the project "Enabling Audiovisual User Interfaces", for which he obtained a Marie Curie EU fellowship. His work has been presented in more than 20 countries.

\section{Introduction}

$A V$ Clash (http://www.avclash.com) is an online project that allows for the integrated playback and manipulation of sound and visuals (Correia, 2010). It was developed by the author and André Carrilho (assisted by Gokce Taskan), under the collective name Video Jack, and released in 2010. The sounds are retrieved from 
Freesound.org, an online sound database, while the visuals were developed by Video Jack. $A V$ Clash is the latest in a series of projects developed by Video Jack that aim to develop a flexible, playful, engaging and intuitive tool for audiovisual creativity. In this series of projects, AV Clash is particularly related to AVOL and Master and Margarita. Video Jack's previous projects had been mostly presented in performances and exhibitions. With these three projects, Video Jack intended to reach a broader audience by additionally using the Internet as a platform, moving into the territory of net art, starting with their project $A V O L$. These projects also challenge the boundaries between author, audience and user. With these projects, Video Jack aspire to stimulate creativity by passing part of the authorial process to their audience.

The three projects fit into a broader cultural context of audience interest in participatory engagement with music; the ascendance of the music video with the emergence of MTV in the 1980s (Austerlitz, 2008, p.31); and increasing importance of Internet as a distribution channel for media, particularly music and music videos. The interest in participatory engagement can be exemplified by the popularity of music games such as the Guitar Hero series, the third most influential game of the past decade according to Wired magazine (Kohler, 2009). As demonstration of the increasing importance of the Internet as distribution channel for music, more than 660 million digital songs were sold in the first semester of 2011 in the USA, an 11 percent increase from the first half of 2010 (Empson, 2011). The Internet has also become "a superb music video resource", contrasting with the mutation of MTV and other music video channels into "a celebration of celebrity and wealth" (Austerlitz, 2008, p.viii).

\subsection{From AVOL to AV Clash}

$A V$ Clash can be considered an evolution of $A V O L$ (AudioVisual OnLine), an earlier net art project by Video Jack, released in 2007. AVOL was one of the four winning projects from a call for proposals by the Arts Department of the Portuguese Ministry of Culture (DGA) for their net art portal. Similarly to $A V$ Clash, $A V O L$ allows for the manipulation of audio and visuals aggregated in seven interactive audiovisual "objects" (IAVOs) incorporating a graphical user interface (GUI), each with playback control functionalities including four main content options (Figures 1, 2). Each IAVO represents a certain type of sound (for example, bass drum and guitar). The visuals in $A V O L$ and $A V$ Clash share multiple common characteristics: they consist of audio-reactive concentric vector animations (28 in $A V O L$, four per IAVO; 96 in $A V C l a s h$ ); the audio reactivity is based on the scaling of animations according to the amplitude of the correspondent sound; and the animations in both projects are abstract, conceived as a subjective interpretation of the type of sound they were meant to represent. Unlike $A V C l a s h$, the audio component in $A V O L$ is fixed-it consists of music loops composed by the author, all with the same length. These loops were composed taking into account that they would be interchangeable. An internal clock ensures that the sounds remain synchronized. These elements contribute to a more traditional "musical" character of $A V O L$, compared to the more chaotic nature of $A V$ Clash, where sounds have different duration and very diverse aesthetics. $A V O L$ possesses basic playback functionality (including stop and solo for each IAVO) and few audio manipulation options - only volume can be controlled. 
Figure 1 Screenshot of AVOL

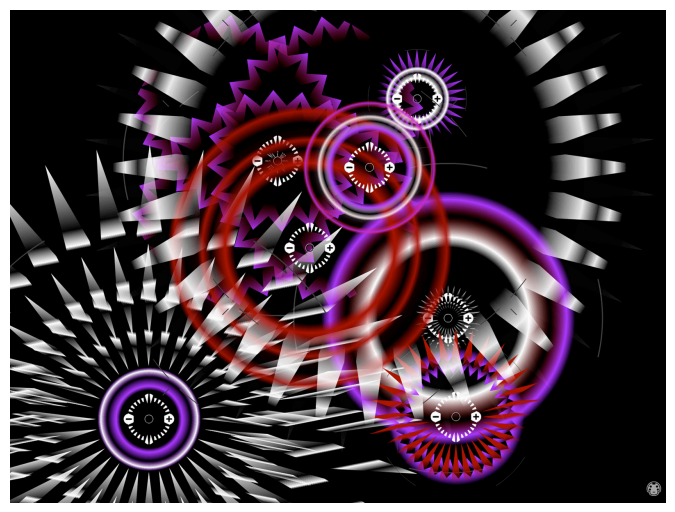

Figure 2 Detail of IAVO in AVOL

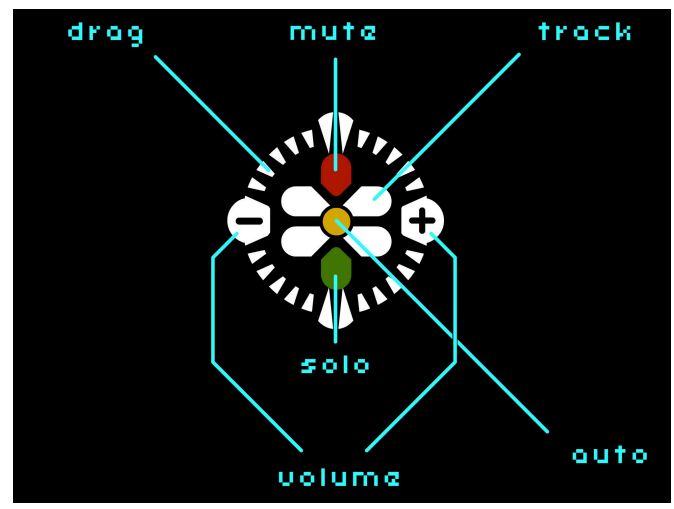

$A V$ Clash was released in 2010. With AV Clash, the author intended to solve some of the weaknesses he detected in $A V O L$ : scarce amount of sounds; inexistent customization of sounds; limited audio manipulation; insufficient playfulness; lack of randomization features; and usability deficiencies. AV Clash addressed those limitations, while maintaining the IAVO approach of integrating GUI with sound visualization and the style of visuals (Figures 3, 4). The number of objects had to be reduced to four due to performance issues. The limitations related to the amount and customization of sounds were addressed by connecting to the online sound database Freesound.org. AV Clash accesses 11 of the tags with the highest number of sounds from Freesound.org (tags such as "noise" and "voice") and retrieves the most popular sounds (according to number of downloads) within those tags. Initially 20 sounds per tag were taken into account, resulting in a total of approximately 240 sounds. As new sounds climb up in popularity they will be added as well. By accessing a menu system, users can change the sounds and animations contained in each object, and even the tag of that object. Four easily accessible pairings of sounds and visuals ("favourites") can be picked for each of the objects (these four pairings are randomized at the start of each session). An additional tag ("avclash") was set up in order to allow users to upload their sounds to $A V C l a s h$, via Freesound.org. Sound manipulation capabilities were added in AV Clash: effects (echo and filter) and sound trimming (start and end points). As an extra element of playfulness, users can "throw" objects around the screen. Because $A V O L$ demanded intensive interaction to obtain substantial change in sound and visuals, a randomization feature was added to AV Clash: a "shuffle" button that randomizes which sound and animation are playing in each object, and moves the object in a random direction, thus enabling a quick change of audiovisual character with a single button press. Another issue addressed in $A V$ Clash was usability. The author felt that the lack of identification of each object in $A V O L$ hindered its ease of use. In $A V$ Clash, objects are identified by colour and by a balloonshaped "info tip" showcasing the tag name. Moving the cursor over an object's button reveals information regarding its functionality. 
Figure 3 Screenshot of AV Clash

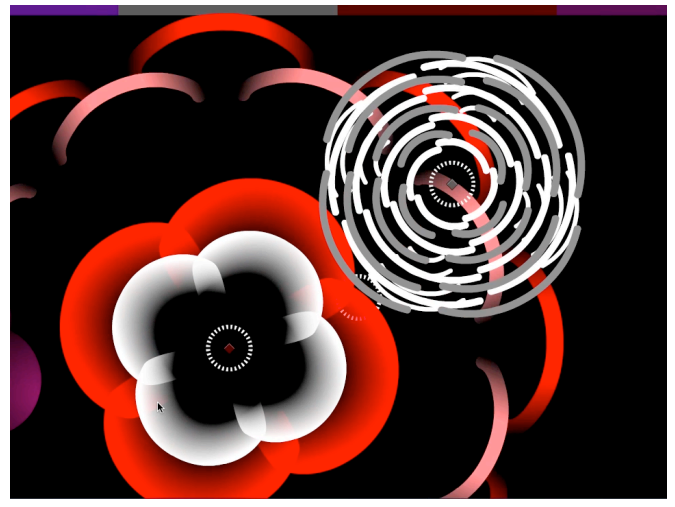

Figure 4 Detail of IAVO in AV Clash

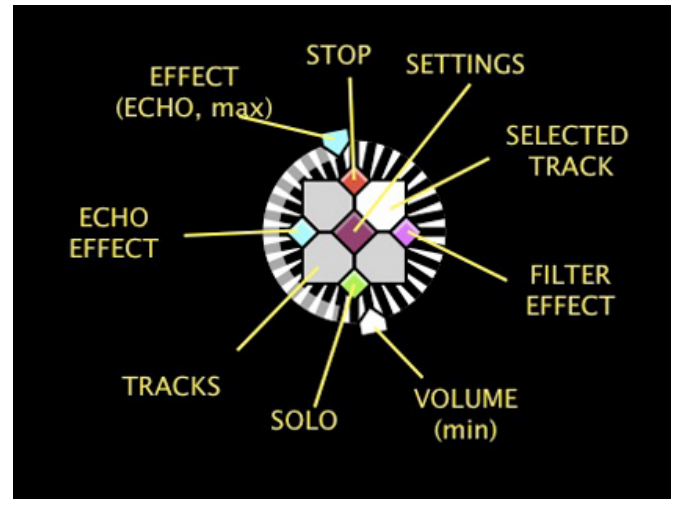

\subsection{From AVOL to Master and Margarita}

In 2009, between $A V O L$ and $A V$ Clash, Video Jack released Master and Margarita, as performance and also as net art project. Master and Margarita can be seen as a figurative "detour" in the path from $A V O L$ to AV Clash. Master and Margarita tried to assess if the IAVO approach that was first attempted in $A V O L-$ of combining sound control with sound visualization in one entity - could be applied to non-abstract visuals, conveying a narrative structure. Video Jack had already created a narrative audiovisual project with interactive animation, Heat Seeker (2006), but the project's software only allowed for interactivity on the visual side. The sound was either triggered and manipulated separately (in performances) or played linearly from start to end (in the web version of the project, released in 2009). Therefore, Master and Margarita aimed to combine the narrative nature of Heat Seeker with the integration of audio, visuals and interactivity of AVOL. Master and Margarita is an adaptation of the book with the same name by Mikhail Bulgakov, a satire of the Soviet society from the pre-Second World War years. It adapts nine of the chapters of the book. There are four IAVOs per chapter, each incorporating only one sound and one animation, resulting in a total of 36 sound loops and audio-reactive animations in the project. Master and Margarita also contains additional visual elements that are not sound reactive. Due to the amount of GUI elements in the project to control the large amount of visuals, and due to a lower amount of sound loops per IAVO (only one, compared to four in $A V O L$ ), the author decided to simplify the GUI in the Master and Margarita IAVOs. One of the solutions implemented was the use of a bi-dimensional fader for volume and size control instead of the plus and minus buttons in $A V O L$. Unlike the abstract visuals of $A V O L$, the IAVO animations in Master and Margarita refer to storyline elements, such as traffic lights, drops of blood, clapping hands, brains, hearts, skulls and crosses (Figures 5, 6). As in AVOL (and $A V$ Clash), the IAVOs are draggable, and their audio-reactivity consists of scaling according to sound amplitude. The random movement mechanism in $A V O L$ was replaced by a random positioning functionality, constrained to a grid. 
Figure 5 Screenshot of Master and Margarita

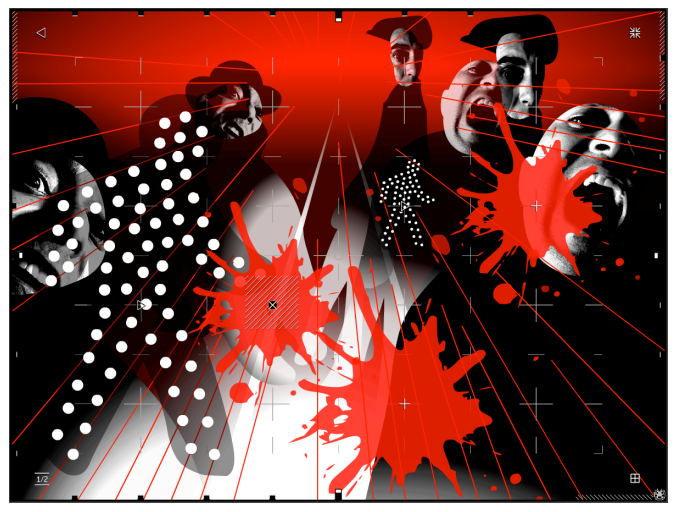

Figure 6 Detail of IAVOs in Master and Margarita

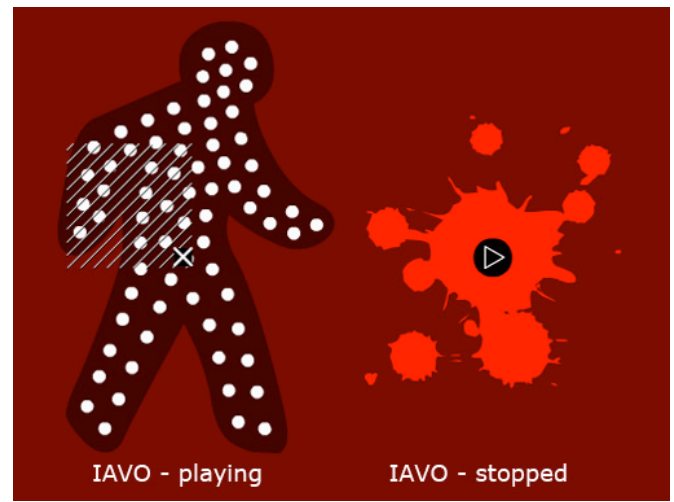

\subsection{From Master and Margarita to AV Clash}

AV Clash incorporated substantially more elements from $A V O L$ than from Master and Margarita. However, a few elements from the latter were adopted: the same number of IAVOs (four); the use of faders instead of plus and minus buttons; and even the connection to Freesound.org as its sound source came partly as a result of the intensive usage of sounds from the online database while composing the soundtrack for Master and Margarita.

\section{Contextualization with related works}

There is a long history behind the dream of combining music with the visual arts, and the pursuit of a correlation between image and sound. Ancient Greek philosophers such as Plato and Aristotle speculated that there was a correlation "between the musical scale and the rainbow spectrum of hues" (Moritz, 1996). In the 19th century, Richard Wagner envisioned a genre of artwork that would combine different arts - a "total art work" (gesamtkunstwerk). Wagner described it as an operatic performance that encompasses music, theatre and the visual arts: "the true Drama is only conceivable as proceeding from a common urgence of every art towards the most direct appeal to a common public". To achieve this, "each separate branch of art can only be fully attained by the reciprocal agreement and co-operation of all the branches in their common message" (Wagner, 2001, p.5).

The development of cinema opened the door to further explorations between music and image. Oskar Fischinger (1900-1967) was one of the notable pioneers of this field and was dedicated to a purely abstract approach of visual representation of music. Fischinger was inspired by Bernhard Diebold, who called for "a new blend of the fine arts, music, dance and cinema - or better, new artists, 'Bildmusikers' [visual musicians]" to achieve Wagner's ideal of gesamtkunstwerk, "preferably abstract in nature" (Moritz 2004, p.4). Fischinger moved to the USA in 1936, where he would work at Disney, in such projects as the "Toccata and Fugue" segment of Fantasia. Walt Disney, however, preferred a "near-abstract" approach to animation instead of a purely abstract one, believing that "you should give something that the audience will recognize" (Moritz, 
2004, p.84). Fischinger's designs were simplified "to resemble some natural form, from a violin to a tin roof to a cloudy sky" (Moritz 2004, p.84), and Fischinger quit Disney, dissatisfied with the experience. When Fischinger moved to the USA, "his work and presence became an inspiration to a second generation of Colour-Music artists" such as Jordan Belson, Harry Smith and brothers John and James Whitney, who decided to take up abstract animation influenced by him (Moritz, 1995).

The development of computing brought about new possibilities for artists in visual music. John Whitney was among the first to explore these possibilities, and his elegant abstract work was an inspiration for the animations in AVOL and AV Clash. Golan Levin is a notable example of a contemporary artist in this field, with projects such as his Audiovisual Environment Suite (AVES), "an interactive software that allows for the creation and manipulation of simultaneous visuals and sound in real time" (Paul, 2003, p.133), using an abstract aesthetics. Levin's influence is apparent in the work of Video Jack, as is Toshio Iwai's figurative approach with Electroplankton, a set of ten "musical toys", each taking place "in some sort of bizarre petri dish—or perhaps a very musical aquarium-filled with different species of plankton that can produce sound and light when you interact with them" (Davis, 2006).

Video Jack are interested in exploring both abstract and figurative aesthetics through animation, rejecting Fischinger's strict preference for pure abstraction. Figurative works by Video Jack such as Master and Margarita owe more to Walt Disney's pioneering Silly Symphonies, which explored combinations of different types of music with animation since the late 1920s (Moritz, 2004, p.83), than to Fischinger's work. The influence of Fischinger's abstract oeuvre can be seen in works such as $A V O L$ and $A V$ Clash. Video Jack agree with Bernhard Diebold's views that "Disney figures, with their

elastic and rhythmic universe, had just as much pointed the way as had the 'absolute films' of Fischinger, Hans Richter, Walter Ruttmann, Lotte Reiniger and others" (Leslie, 2006).

\section{Methodology and framework}

Between April and May 2011, an online questionnaire was conducted to determine if $A V$ Clash had succeeded in its objectives, as defined by the research question it addresses: how to create a tool for integrated audiovisual creativity, with customizable content, that is flexible, intuitive, playful to use and engaging to observe? Because some of the objectives are related to solving insufficiencies detected in previous projects, the questionnaire included sections comparing $A V$ Clash to earlier projects by Video Jack: Master and Margarita and AVOL.

\subsection{Structure of the questionnaire}

The different elements of the research question $A V$ Clash addresses structured the sections of the questionnaire: 1) audiovisual integration and type of content; 2) amount of content; 3) flexibility of manipulation; 4) usability, intuitiveness and exploration; 5) creativity and experience. Each section included questions comparing $A V$ Clash with previous projects. Because $A V$ Clash is particularly related to $A V O L$, the latter project 
was mainly used in these comparisons. However, Master and Margarita was also used for comparison in section 1), related to visual content and different visual approaches. The questionnaire was composed of 81 questions, mostly close-ended, but also openended ones (13). For this article, the 17 comparison questions and the 13 questions related to future developments are taken into account.

\subsection{Usability and experience-focused HCI}

In order to develop the different sections of the questionnaire, literature on experience-focused human-computer interaction (HCI) and usability were important sources. Experience-focused literature has detected gaps between HCI methodologies and the ones used by new media artists. On the one hand, some authors identify a tendency in interactive art to ignore HCI methodologies for interaction, "based on a mostly unstated belief that they do not measure aspects of interactive artworks that are of interest to artists" (Höök et al., 2003, p.241). Höök et al. consider that user studies can assist artists "that want to express themselves through an interactive system" to make the interaction "work as intended" (2003, p.248). On the other hand, some authors note that evaluation of experienced-focused applications should go beyond usability: "to evaluate merely on usability is to miss the very point of these technologies" (Kaye et al., 2007, p.2118).

As a consequence, the field of HCI has been developing the concept of experiencefocused HCI, "recognizing a widening of the sphere of HCI out of the workplace and into the world, and emphasizing the importance of culture, emotion, and lived experience" (Kaye et al., 2007, p.2118). Following in this direction, Peterson et al. propose the notion of aesthetic interaction as an "extended expressiveness towards interactive systems", that would reach "beyond ideals of efficiency and transparency, e.g. like considering the emotions, attraction, and affect invoked by design" (Petersen et al., 2004, p.269). It is focused on "intriguing and sometimes even ambiguous aspects", and it aims to

"encourage the user to explore and playfully appropriate the system", by "creating involvement, experience, surprise and serendipity in interaction" (Petersen et al., 2004, p.274). Explorability was indeed an important aim in the design of the projects, since, as Donald Norman states, "one important method of making systems easier to learn and use is to make them explorable, to encourage the user to experiment and learn the possibilities through active exploration" (Norman, 2002, p.183).

\section{Results}

The answers to the survey were anonymous. The questionnaire was answered by 22 respondents. Approximately two thirds of the respondents had a master's degree. The vast majority $(91 \%)$ of these test users had experience as new media artist and/or new media designer. Half had experience as DJ (disk jockey) and/or musician. All had experience as viewers/listeners of new media art projects and of net art projects. Therefore, the respondents appear to be experienced users of interactive content and familiar with media production. On average, the respondents have used $A V$ Clash two times and spent 12 minutes playing with the project per session. 


\subsection{Audiovisual integration and type of content}

Comparison with two previous Video Jack projects, particularly Master and Margarita, can be useful in order to identify issues related to abstract and figurative content. Do purely abstract visuals contribute to a more satisfying experience compared to figurative visuals, as some visual music artists argue? And does the more chaotic and less conventionally character of the sound in $A V$ Clash provide a more satisfactory experience, particularly comparing with $A V O L$ ?

Nearly two thirds of the respondents $(64 \%)$ answered that $A V$ Clash integrates sound and image better than Master and Margarita (Figure 7). Only four respondents chose the latter, with another four answering that they are in the same level regarding this issue. Two of the four respondents who picked Master and Margarita enjoy the meaning added to the sound by the visuals: one refers that the animations in the project "are icons that come to represent the sound, instead of patterns reacting differently to sounds", the other states that "the visuals give more context to the sound". An additional test user prefers the "simpler" visuals of the project, while the remaining one prefers the approach of Master and Margarita because it is "more an art piece than a tool" and more "random". From the respondents who picked $A V$ Clash, two prefer the "free flow" of $A V$ Clash, expressing preference for its "organic" approach (less structure, no grid). One of the users expresses preference for the abstract nature of $A V$ Clash, with another one stating that it looks more "neutral". Although it is apparently an unrelated topic, three of these test users state that $A V$ Clash is easier to use.

Figure 7 Comparing audiovisual integration in AV Clash and Master and Margarita

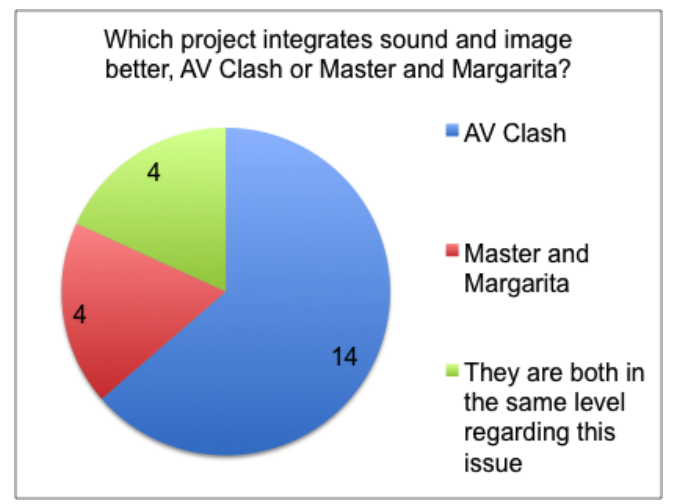

Figure 8 Comparing audiovisual integration in AV Clash and AVOL

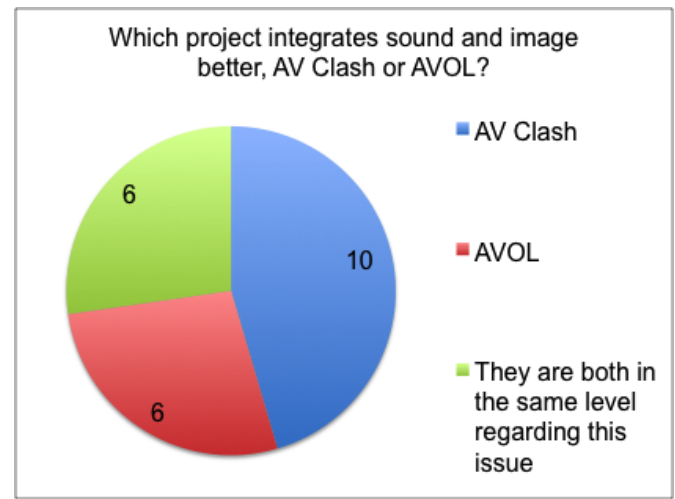

Previous abstract project $A V O L$ comes closer to $A V$ Clash in terms of sound and image integration (Figure 8). AV Clash is considered to integrate the two elements better by around half of the respondents, while approximately one-fourth answered $A V O L$, and an equal percentage of users consider them to be in the same level. From the six test users who preferred $A V O L$, four mention the issue of simplicity, with one user elaborating further: "the connection with the sound is more simple and more obvious". Two of these test users replied that the end result was more appealing. From the respondents who expressed preference in the sound and image integration in $A V C l a s h$, three answered that the project, in terms of interface and logic, was easier to understand. Two of the respondents justified their choice due to a higher amount of manipulation options. 
When asked explicitly if they preferred abstract or figurative visuals, approximately half of the respondents expressed preference for abstract visuals, whereas the other half preferred abstract and non-abstract, mixed. Only two test users preferred exclusively nonabstract visuals. Approximately half of the respondents prefer the visual style of $A V$ Clash to the style of Master and Margarita, whereas nearly one third prefers the visual approach of the latter. Only two users enjoy equally both. Respondents who prefer the visuals of Master and Margarita mention that they have a larger variation of material; a higher distinctiveness and originality; are more "fun"; are more "conductive to bodily movement" (whereas AV Clash visuals would be more meditative); are less predictable; besides the well-accomplished narrative and "a great interpretation of the novel's content" as factors for their preference. Four of the test users that favoured the visuals in AV Clash mentioned that they enjoyed the abstract visuals more, while three manifested a dislike for the visuals in Master and Margarita. Another mentioned that AV Clash was more consistent.

The results are slightly more balanced when comparing the sonic approach of $A V$ Clash with the one in $A V O L .41 \%$ of the test users prefer the sound and music approach of $A V$ Clash, against $32 \%$ who prefer the approach of $A V O L$, with $27 \%$ enjoying equally both. The test users who preferred the sounds in $A V O L$ stated that the synchronization of the loops, the fact that the sounds were curated, and the inclusion of percussive elements were factors for their choice. Three test users who preferred AV Clash mentioned the variety of sounds (and another one mentioned its lack in $A V O L$ ), while two mentioned the higher level of control as reasons for their preference. Another respondent preferred the sounds in $A V$ Clash because they were "more abstract and neutral". One of the users who enjoyed equally both mentioned that while $A V O L$ offers more harmony due to its preselected set, $A V$ Clash offers more variety. Another respondent who also manifested equal preference mentioned that $A V O L$ was better for rhythm due to loop synchronization, while for other type of sounds $A V$ Clash was preferable due to its larger amount of content. One user preferred $A V O L$ due to the larger number of control possibilities, which reveals there were aspects of $A V$ Clash that remained undiscovered (since it is the latter that offers more control functionalities).

\subsection{Amount of content}

One of the main aims of $A V$ Clash was to increase substantially the number of sounds that could be accessed, compared to $A V O L$. One of the sections of questionnaire concentrated on this aspect. Approximately two thirds (68\%) of the respondents consider that the possibility of accessing a larger amount of content in $A V$ Clash than $A V O L$ is appealing, against $27 \%$ who do not (Figure 9). 
Figure 9 Appeal of additional content in AV Clash

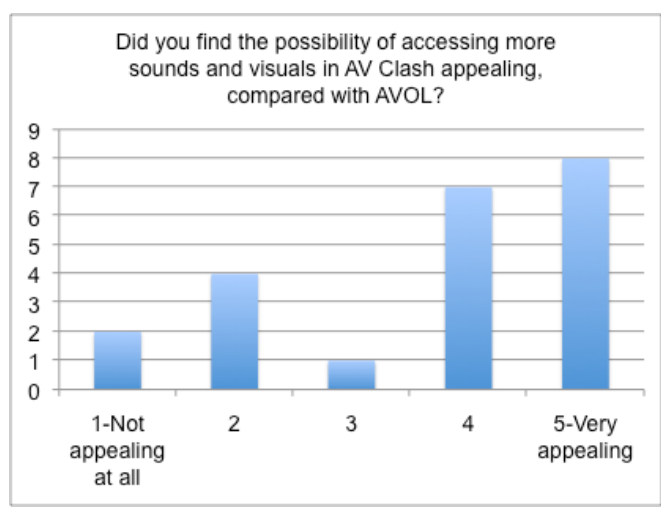

Figure 10 Comparing appeal of additional content (y axis) with number of interaction sessions (x axis)

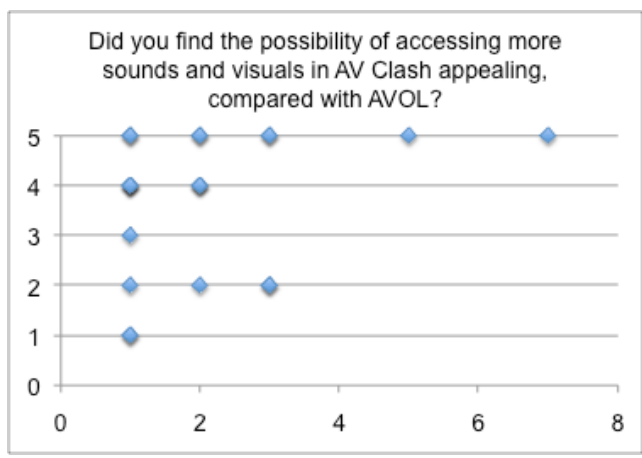

In $A V$ Clash, most of the content is not immediately accessible or visible (only 16 sounds and animations are). To access the extra content, users have to press a "settings" button. More experienced users are assumed to discover this additional content, and value it more, while novice users may be less likely to do so. Following the conclusions of Kiefer et al., who state that allotted practice time is particularly important in a musical usability study $(2008$, p.89), the duration of interaction with the system (measured by the number of interaction sessions) was correlated with the appeal of additional content. Even though correlation analysis did not reveal any substantial relationship between both, a graphic comparing number of interaction settings with the appeal of additional content reveals that users who have interacted more with $A V$ Clash tend to find the additional content very appealing, with a more varied range of responses for those who have interacted less (Figure 10). This leads to the conclusion that the diversity of content in $A V$ Clash may remain undiscovered for novice users.

\subsection{Flexibility, usability and intuitiveness}

Besides increasing the amount of content compared to AVOL, AV Clash also aimed to increase the amount of sound manipulation capabilities, such as "echo" and "filter" audio effects and sound trimming. A section of the questionnaire was dedicated to assessing if the test users valued these developments. Comparing AV Clash to AVOL, half of the test users consider the additional audio manipulation options in the former to be interesting, against $18 \%$ who did not. Nearly one quarter of the respondents are indifferent (Figure 11). 
Figure 11 Appeal of additional audio manipulation in AV Clash

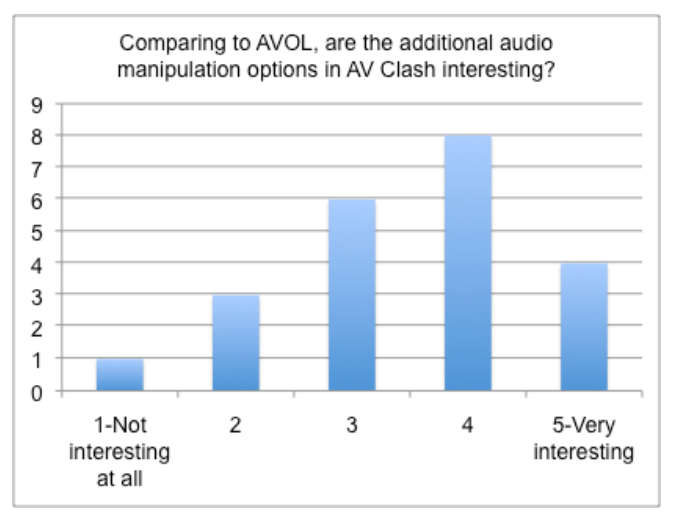

Figure 12 Comparing appeal of additional manipulation options ( $\mathrm{y}$ axis) with number of interaction sessions ( $\mathrm{x}$ axis)

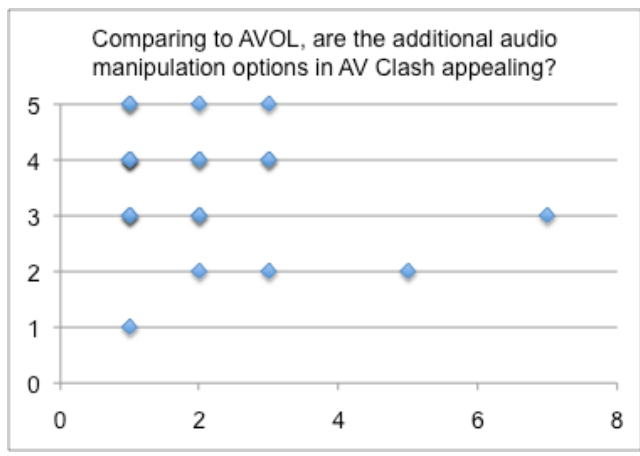

Approximately three quarters of the test users have spent more time interacting with $A V$ Clash than with $A V O L$. When asked about the reason for this preference, in a multiple-choice question, $73 \%$ of the respondents mentioned the larger amount of manipulation options, while $40 \%$ mentioned the larger amount of content. $47 \%$ of the users indicated "other", and these were asked to elaborate. One of the users stated "the interface felt clearer, and easier to learn and manipulate". To assess if more time spent interacting with $A V$ Clash would lead to a higher interest in audio manipulation options, the number of interaction sessions were compared with the appeal of the added functionalities (regarding $A V O L$ ). Unlike the added audio content, appreciation for the extra audio manipulation options does not seem to increase with more interaction sessions (Figure 12). One possible explanation is that most of the audio manipulation options are immediately available (simply by dragging faders on the IAVOs), unlike most of the added content, which requires further exploration (accessing the settings area).

The additional options in $A V$ Clash, compared to $A V O L$, created a challenge: how to add functionalities to $A V O L$ while improving the usability? A section of the questionnaire compared the ease of use of $A V O L$ and $A V$ Clash. The answers are evenly split. Around one third of users consider $A V$ Clash to be more intuitive to use, whereas a similar percentage reply that $A V O L$ is more intuitive. More than one-fourth consider that they are on the same level regarding intuitiveness. When asked the reasons behind their choices, six out of the eight users who considered $A V O L$ more intuitive mention the simpler interface and fewer options as the reasons for their choice. Three of the users who found $A V$ Clash more intuitive manifested preference in the project's UI.

\subsection{Creativity and experience}

All the previous aspects - multisensoriality, type and amount of content, manipulation options, ease of use-aim to contribute to engagement, playfulness and creativity. Particularly important was to evaluate the degree of creativity allowed by $A V$ Clash: did the new features added to $A V$ Clash contribute to a more creative experience than $A V O L$, as it aimed to?

As previously mentioned, nearly three quarters of the users have spent more time interacting with $A V$ Clash than with $A V O L$ (Figure 13). More than half (59\%) of the respondents consider that $A V$ Clash gives a higher feeling of creativity, whereas two 
respondents chose $A V O L$. Around one quarter answer both, and two test users answered that they do not get a feeling of creativity from either (Figure 14). Of the 13 respondents who consider that $A V$ Clash gives a greater feeling of creativity than $A V O L$, seven mention more control or more options and one respondent mentions more variety in sound. One of the respondents who answered that both projects give the same feeling of creativity considers that both projects shape the sound and visuals too much to allow for their own creativity, and one of the users who did not get a feeling of creativity from either mentions that the projects are "too structured". One of the two test users who consider $A V O L$ to offer a more creative experience mentions that the selected sounds "fit together nicely", adding that switching between them created interesting results.

Figure 13 Comparing time spent interacting with AV Clash and AVOL

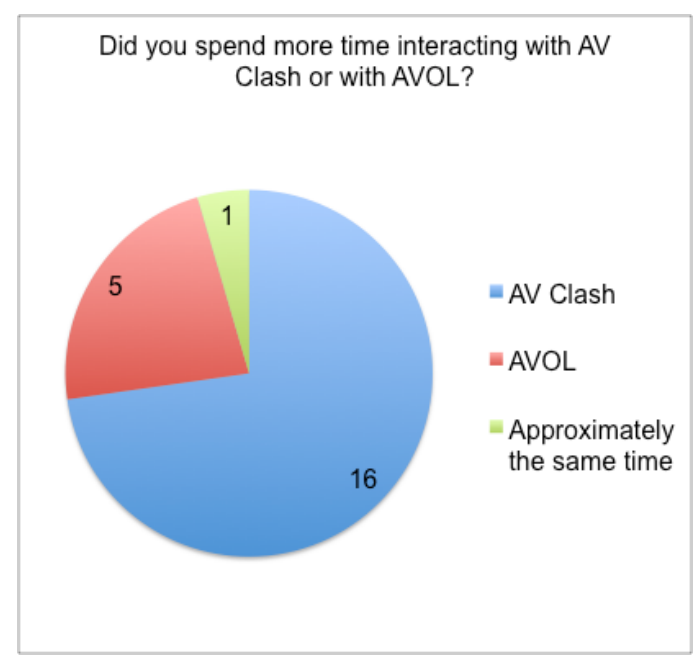

Figure 14 Comparing feeling of creativity perceived from experiencing AV Clash and AVOL

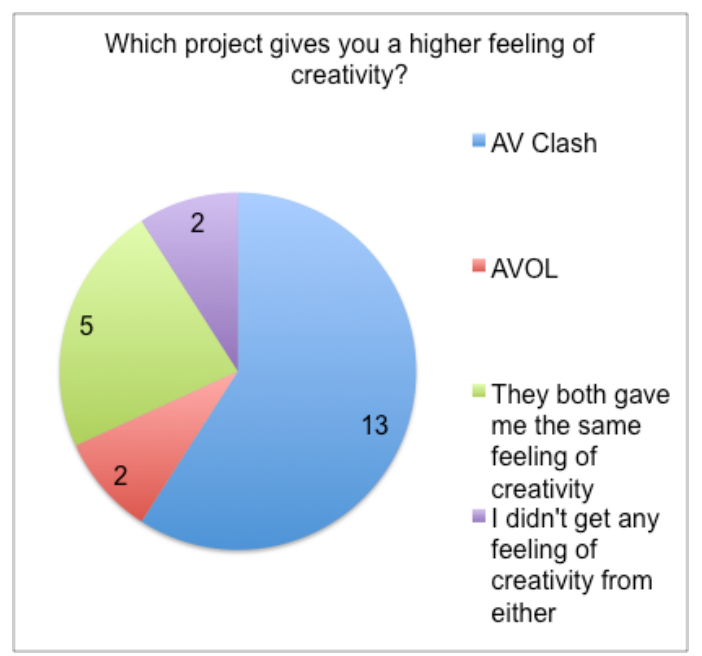

\subsection{Future developments}

The final section of the questionnaire was dedicated to exploring possible future developments of $A V$ Clash. Test users were questioned regarding what functionalities they found attractive to be added to the project, by selecting from a list or writing their own suggestions.

Regarding suggestions for new functionalities, recording audio/video or saving options (picked by 64\% of the respondents) and sharing recordings by e-mail or social networks (selected by $73 \%$ of the users) are among the most desired additions. Visual customization (drawing or uploading visuals) is important for $73 \%$ of the respondents, whereas sound input is relevant for $59 \%$ of the test users. The lower diversity of visuals in $A V$ Clash compared with the diversity of sounds can explain a stronger wish for visual customization. Concerning other platforms for using $A V$ Clash, 64\% of the respondents would like to use it as installation, whereas approximately half would wish to see $A V$ Clash adapted to other devices, such as games consoles or mobile phones. Collaborative functionalities would also be important for approximately half of the respondents. Users seem to be less interested in increased manipulation capabilities ( $46 \%$ consider it important), higher diversity of content (only 19\% consider useful to add more tags to the 
12 existing ones) and more random functionalities (one third of the respondents regard this as an important aspect).

When asked to freely suggest future developments for $A V$ Clash, three of the respondents suggested usability improvements, such as: better indication of what areas can be clicked on; increasing the size of the buttons; adding more explanatory texts to interactive elements; adding keyboard shortcuts; and adding an "intro mode" with more explanations and tool tips. Five other test users suggested feature additions. Some of these additions coincided with the ones presented in the multiple answer questions, while others went beyond those, such as: using the spatial coordinates of the screen to affect some parameters; using physics when throwing; adding a sound synthesis engine with short midi patterns; and adding a master volume slider.

\section{Conclusions}

The answers to the questionnaire might be biased towards favouring $A V$ Clash. As it was the most recent project, and the focus of most of the questions, respondents might have spent more time interacting with it. Additionally, the number of the respondents to the questionnaire was low (22), limiting the extrapolation of results and the achievement of more generic conclusions. The length of the questionnaire (81 questions) might have intimidated other potential respondents. In any case, the results offer insights to important issues related to interactive audiovisual projects, such as: usage of abstract and figurative visuals; amount of content; functionalities; usability; and experience. They also point the way for future developments in this path. Tentative conclusions are reached regarding different profiles of users. Taking into account experience-focused HCI perspectives in the evaluation of the three net art projects, while contemplating usability issues, was important in order to cover a wide range of topics.

\subsection{Conclusions regarding the objectives of AV Clash}

The results of the questionnaire show that $A V$ Clash was more successful than Master and Margarita and $A V O L$ in the integration of sound and visuals. Two thirds of the respondents chose $A V$ Clash over Master and Margarita regarding this issue, with $A V O L$ coming closer (half of the respondents chose $A V$ Clash). This might indicate that abstraction (the style used in $A V$ Clash and $A V O L$ ) is a preferred style of music visualization. However, although nearly half of the respondents did manifest a preference for purely abstract visuals, respondents also find the visuals in $A V$ Clash lacking in diversity, with nearly half of the respondents manifesting a preference for abstract visuals mixed with figurative ones, instead of a purely abstract or figurative approach. In terms of audio, comparing the chaotic and diverse approach of $A V$ Clash with the more conventional and synchronized nature of the music loops in $A V O L$ leads to nearly balanced results ( $41 \%$ prefer the former, and $32 \%$ the latter).

$A V$ Clash seems to have been successful in its aim of creating a more engaging experience than $A V O L$ by offering a larger variety of content and more manipulation options. Two thirds of the users find the possibility of accessing more content attractive. Three quarters of the test users have spent more time interacting with $A V$ Clash than with 
$A V O L$, and a majority of these $(73 \%)$ chose the larger number of manipulation options as the main reason for the extra time spent with AV Clash (with $40 \%$ choosing the larger amount of content as the main reason). The majority of respondents (59\%) obtain a higher feeling of creativity from $A V$ Clash than from $A V O L$. However, AV Clash did not succeed in improving the usability of $A V O L$. When asked which one was easier to use, users were evenly split between the two projects. The improvements in usability that were introduced ("info tips", colour coding of IAVOs) seem to have been offset by the complexity of the added functionalities.

\subsection{Strengths detected in AVOL and Master and Margarita}

Although $A V$ Clash was the most successful project for the majority of users in the different sections of the questionnaire (except usability), it is important to analyse why a still significant minority of users preferred $A V O L$ or Master and Margarita.

As was presented, $A V O L$ obtained equal results to $A V$ Clash in terms of ease of use (Figure 15). When asked for the reasons behind their answer, six out of the eight users who consider $A V O L$ more intuitive mention the simpler interface and fewer options of the project. Four of the six users that prefer the connection of sound and visuals in $A V O L$ favour its "simplicity", while two find the end result more appealing (presumably on the sonic side, as the visual side is aesthetically similar). The one third of respondents who prefer the sonic approach of $A V O L$ appreciated the synchronization and harmony of sounds ("they fit together nicely", as one user put it) and rhythmical nature. A project with a limited set of options and simple interface, and with a harmonious, wellsynchronized audiovisual content, can be as appealing as a more complex and diverse one. For some (although a minority according to this study), more content and more manipulation options do not lead to a higher engagement.

Users who prefer the visual style of Master and Margarita (one third) mention that the project's visuals have a larger variation of material; a higher distinctiveness and originality; and are more "fun" and unpredictable. The preference for the figurative approach is further elaborated in the following user statements: Master and Margarita is considered to be "a great interpretation of the novel's content", where the "visuals give more context to the sound", with "icons that come to represent the sound". A significant amount of users prefer visuals combining abstract and figurative elements, breaking away from Fischinger's ideal of a purely abstract visual music (Figure 16). One user stated that Master and Margarita is "more an art piece than a tool", which seems to indicate that the project has a strong character, not easily allowing to be shaped by the users (with positive and negative implications, depending on the creative freedom they desire). The strengths of Master and Margarita appear to be the combination of sound with figurative visuals and the diversity of its content, while maintaining a distinctive character, partly due to the literary adaptation. 
Figure 15 Comparing ease of use of AV Clash and AVOL

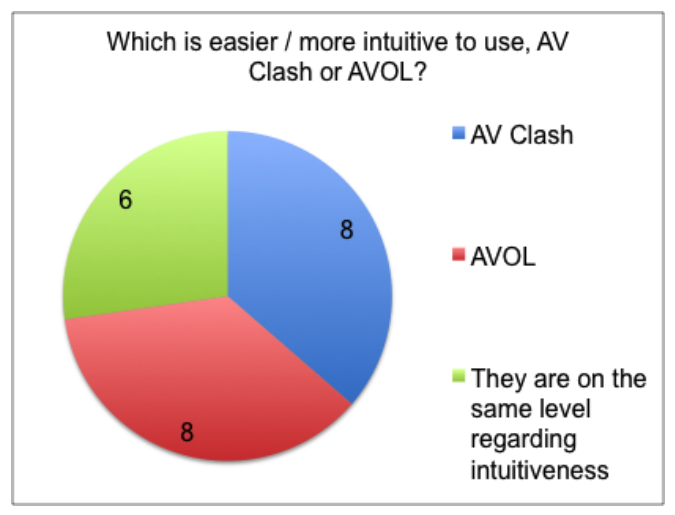

Figure 16 Comparing preference for abstract or figurative visuals

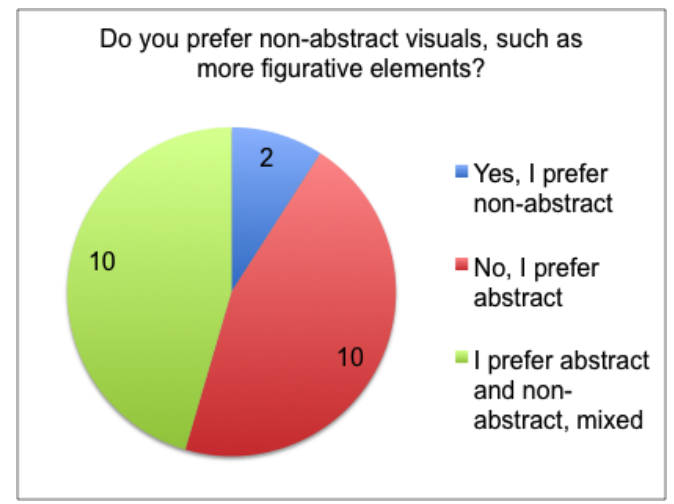

The results of the questionnaire show that, while most of the users were more pleased with $A V$ Clash than with the previous two projects, there are still those who prefer simplicity of usage and harmony of content (as in $A V O L$ ), and those who prefer a figurative style with diversified visuals sharing a coherent character (Master and Margarita). Adding functionalities and content might be attractive for some users, but others prefer a simpler, more curated approach (either abstract or figurative). $A V O L$ and $A V$ Clash in particular represent a trade-off: simplicity of usage, synchronization and harmony of content in the former, versus diversity of options, variety and unpredictability of content in the latter, with users positioning themselves differently in their preferences.

There seem to be three groups of users: those who prefer the simpler approach of $A V O L$ (and to a certain extent of Master and Margarita); those who are happier with the higher diversity and options of $A V$ Clash; and one third group of users that feel that they are "too structured to allow for creativity", as one of the users expressed. Future interactive audiovisual applications (such as further developments of $A V C l a s h$ ) could contemplate this third group, by providing more customization options and more content (particularly on the visual side). The identification of these three groups, with different demands regarding content and functionalities, might be important in terms of targeting future interactive audiovisual projects.

\subsection{Future developments}

Paths for future developments of $A V$ Clash should contemplate wishes expressed by the respondents, and these might be relevant for other audiovisual projects. Recording audiovisual sessions and sharing these by email or social networks would be attractive features for, respectively, $63 \%$ and $73 \%$ of the users. This could be accomplished by adding a "sequencer" (editable or not) that would record all the steps taken by the user, retrievable with a custom URL, or simply by recording video files, with the option of uploading them to sites such as YouTube.

Possibly due to the lesser variety of the visuals compared with the audio, developments in visual customization would be important for $73 \%$ of the respondents. A solution for this could be the creation of a drawing area within the project that would generate vector animations, or the creation of a vector drawing and animation database, which would be an adequate counterpoint to the sound database in Freesound.org. The 
preference for a mixture of abstract and figurative visuals, stated by half of the respondents, suggests that it could be appealing to combine the figurative aesthetics of Master and Margarita with the large amount of content and manipulation options of $A V$ Clash.

Other platforms should also be explored for $A V C l a s h$, or similar future interactive audiovisual projects. Nearly two thirds of the respondents would like to use it as installation, and approximately half would enjoy using $A V$ Clash in other platforms such as games consoles or mobile devices. Multi-touch screen platforms such as iOS and Android devices seem to be particularly appropriate to the IAVO approach, as users would be manipulating the visualizations more directly with their fingers. Collaborative functionalities, allowing for networked composition for example, could also be added, as these are considered important for approximately half of the respondents.

However, care should be taken when adding new functionalities. Users seem to be less attracted to adding more manipulation options, or to adding content, than to improvements in ease of use. Usability problems seem to be quite relevant - it is an issue that often appears under the open-ended questions, even in the section related to future developments. These problems confirm the importance of user studies in art projects, as Höök et al. have advocated (2003). Improvements in the interaction design should encourage users to better "experiment and learn the possibilities through active exploration" (Norman, 2002, p.183). Future developments of AV Clash, and similar audiovisual projects, should particularly foster the explorability of content.

\section{References}

Austerlitz, S. (2008). Money for Nothing: A History of the Music Video from the Beatles to the White Stripes. New York: Continuum.

Correia, N.N. (2010). AV Clash - Online Tool for Mixing and Visualizing Audio Retrieved from Freesound.org Database. In: Proceedings of Sound and Music Computing Conference 2010. Barcelona, pp. 220-226. Available at: http://smcnetwork.org/node/1365. [Accessed: 6 June 2011].

Davis, R. (2006). Electroplankton Review. Gamespot. Available at: http://www.gamespot.com/ds/puzzle/electroplankton/index.html. [Accessed: 22 August 2011].

Empson, R. (2011). Say What? Thanks To Digital Music, Album Sales Up For The First Time Since 2004. TechCrunch. Available at: http://techcrunch.com/2011/07/06/say-what-thanks-to-digital-music-album-salesup-for-the-first-time-since-2004/. [Accessed: 21 August 2011].

Höök, K., Sengers, P. \& Andersson, G. (2003). Sense and sensibility: evaluation and interactive art. In: Proceedings of the SIGCHI conference on Human factors in computing systems. Ft. Lauderdale, pp. 241-248. Available at: http://portal.acm.org/citation.cfm?id=642654. [Accessed: 25 March 2011].

Kaye, J. "Jofish," Boehner, K., Laaksolahti, J. \& Staahl, A. (2007). Evaluating experience-focused HCI. In: CHI '07 extended abstracts on Human factors in computing systems. New York, pp. 2117-2120.

Kiefer, C., Collins, N. \& Fitzpatrick, G. (2008). HCI Methodology For Evaluating Musical Controllers: A Case Study. In: NIME08 Proceedings. Genova, pp. 87-90. 
Available

http://nime2008.casapaganini.org/documents/Proceedings/Papers/193.pdf.

[Accessed: 25 March 2011].

Kohler, C. (2009). The 15 Most Influential Games of the Decade. Wired. Available at: http://www.wired.com/gamelife/2009/12/the-15-most-influential-games-of-thedecade/all/1. [Accessed: 20 August 2011].

Leslie, E. (2006). Where Abstraction and Comics Collide. Tate Etc. Available at: http://www.tate.org.uk/tateetc/issue7/fischinger.htm. [Accessed: 12 August 2011].

Moritz, W. (1995). Color Music - Integral Cinema. In: Poétique de la Couleur. Paris: Musée du Louvre. Available at: http://www.centerforvisualmusic.org/WMCM_IC.htm. [Accessed: 22 August 2011].

Moritz, W. (2004). Optical Poetry: The Life and Work of Oskar Fischinger. Eastleigh: John Libbey Publishing.

Moritz, W. (1996). The Dream of Color Music, And Machines That Made it Possible. Animation Journal. 4 (2). pp. 69-84.

Norman, D. (2002). The Design of Everyday Things. New York: Basic Books.

Paul, C. (2003). Digital Art. London: Thames \& Hudson.

Petersen, M.G., Iversen, O.S., Krogh, P.G. \& Ludvigsen, M. (2004). Aesthetic interaction: a pragmatist's aesthetics of interactive systems. In: Proceedings of the 5th conference on Designing interactive systems: processes, practices, methods, and techniques. New York, pp. 269-276.

Wagner, R. (2001). Outlines of the Artwork of the Future. In: R. Packer \& K. Jordan (eds.). Multimedia: From Wagner to Virtual Reality. New York: W. W. Norton, pp. 3-9. 